\title{
La France et la première abolition de l'esclavage (1794-1802) [le cas des colonies orientales, île de France (Maurice) et la Réunion]
}

\section{Claude Mazauric}

\author{
CpenEdition \\ Journals \\ Édition électronique \\ URL : https://journals.openedition.org/ahrf/925 \\ DOI : 10.4000/ahrf.925 \\ ISSN : 1952-403X \\ Éditeur : \\ Armand Colin, Société des études robespierristes \\ Édition imprimée \\ Date de publication : 1 septembre 1999 \\ Pagination : 552-554 \\ ISSN : 0003-4436 \\ Référence électronique \\ Claude Mazauric, "La France et la première abolition de l'esclavage (1794-1802) [le cas des colonies \\ orientales, île de France (Maurice) et la Réunion] », Annales historiques de la Révolution française [En \\ ligne], 317 | juillet-septembre 1999, mis en ligne le 10 avril 2006, consulté le 24 avril 2022. URL : http:// \\ journals.openedition.org/ahrf/925; DOI : https://doi.org/10.4000/ahrf.925
}

Ce document a été généré automatiquement le 24 avril 2022.

Tous droits réservés 


\title{
La France et la première abolition de l'esclavage (1794-1802) [le cas des colonies orientales, île de France (Maurice) et la Réunion]
}

\author{
Claude Mazauric
}

\section{RÉFÉRENCE}

Claude WANQUET, La France et la première abolition de l'esclavage (1794-1802) [le cas des colonies orientales, île de France (Maurice) et la Réunion], Paris, Karthala, 1998, 664 pp. + bibliographie, chronologie et index nominum + tables.

1 Une somme. Dans le flot des ouvrages et essais qui ont accompagné la «Commémoration» du 150e anniversaire de l'abolition de l'esclavage dans les colonies françaises, le gros livre de Claude Wanquet se signale par la largeur de ses vues, qui débordent de loin le seul cas des colonies orientales, et l'extrême précision de ses analyses. Largeur de vues? Telles sont les trente premières pages du livre qui balaient la question des processus conduisant au décret du 16 pluviôse an II aussi bien que la cinquième partie (pp. 529 à 648) qui traite de la longue hésitation de Bonaparte entre appliquer l'abolition et sa révocation, point d'arrivée de «l'inexorable dérive esclavagiste du régime consulaire» (p. 635). Extrême précision érudite des analyses? Tout ce qui concerne l'histoire propre des Mascareignes auxquelles, en raison même de la prédominance des problèmes posés par les colonies occidentales, Saint-Domingue mais aussi la Martinique, la Guadeloupe et les autres Antilles, on n'avait jusqu'alors accordé que trop peu d'importance. Il est vrai que leur commerce avec la France n'avait rien de comparable à celui qui liait la métropole aux colonies occidentales. Mais ce qu'on découvre à lire le Wanquet, c'est l'étonnante habileté (la «virtuosité» écrit l'auteur) avec laquelle les colons des îles de l'océan Indien savent jouer des ambiguïtés d'un discours qui n'exclut pas de prendre en considération les thèses abolitionnistes, 
qui affiche sans hésiter profession de foi patriotique voire républicaine - notamment à propos de la menace anglaise - mais n'en exige pas moins des lois particulières pour les colonies, conduisant à préserver «transitoirement» l'esclavage jusqu'à la mise en place de mesures propres à indemniser les propriétaires et à réorienter l'économie des Mascareignes. Selon Claude Wanquet, si les colons de l'océan Indien et leurs représentants à Paris ont pu si aisément jouer de l'ambiguïté, c'est que les rivalités entre montagnards, bientôt thermidoriens, les ambitions politiques des uns et des autres et l'identification de l'abolitionnisme au girondinisme, ont empêché de donner au décret du 16 pluviôse, toute sa dimension pratique. En sorte qu'en septembreoctobre 1795, au début de l'an IV, rien n'avait encore été décidé quant à l'application aux Mascareignes du décret d'abolition! Pourtant, au terme du «grand débat» colonial de l'an III qui, de portée stratégique, avait posé la question de savoir comment agir aux colonies dans le nouveau contexte international et intérieur, la Convention sur rapport de Boissy d'Anglas, était engagée dans la voie de l'assimilation des colonies au cadre principiel, constitutionnel et réglementaire de la République: on aurait donc dû ne pas pouvoir échapper à l'application d'une politique abolitionniste puisque la Déclaration des droits et des devoirs, placée en tête de la Constitution de l'an III, condamnait l'esclavage... C'était sans compter sur l'obstination et la capacité de dissimulation des colons qui réussirent à tenir en échec toutes les entreprises allant dans le sens d'une abolition, notamment à l'occasion de la mission de Baco et Burnel. Une escadre de quatre navires et deux corvettes, emmenant 780 hommes de troupe atteignit PortNord-Ouest le 30 prairial an V (18 juin 1796). L'opposition d'abord ferme et assez vite quasi insurrectionnelle des colons comme Villèle, opposés à l'application de la législation constitutionnelle (donc abolitionniste) obligea les représentants de la République à rembarquer et à regagner Rochefort où ils débarquèrent le $5 \mathrm{e}$ jour complémentaire (22 septembre). Contre l'opinion de divers auteurs, notamment Florence Gauthier, Claude Wanquet, sans surestimer la fermeté de Baco et Burnel, insiste néanmoins sur la détermination des colons qui paraît avoir impressionné les cadres du corps expéditionnaire. Au cours de leur voyage de retour, dernier camouflet, Baco et Burnel reçurent la preuve que la traite française s'était poursuivie dans l'océan Indien, malgré les affirmations contraires des assemblées coloniales (cf. p. 309)! La poussée de la droite clichyenne en l'an $\mathrm{V}$ relança le débat colonial mais cette fois-ci avec la claire perspective de rétablir l'esclavage: cette campagne aurait assurément conduit à «blanchir» les colons rebelles des Mascareignes en leur donnant raison et à préparer le retour de l'esclavagisme là où on l'avait aboli mais elle échoua et ce fut la défense néojacobine qui mit en échec la politique prévue. Les îles de l'océan Indien, parallèlement, retrouvaient de l'intérêt car à la suite de l'expédition de Bonaparte en Égypte, les "rêves orientaux» donnaient consistance à l'idée de construire aux Mascareignes une solide base stratégique française, propre à soutenir en l'utilisant la révolte anti-anglaise dans le sub-continent indien. L'échec du projet Monneron cependant puis la crise finale du Directoire, conduisirent au maintien du statu quo, malgré toutes les incertitudes qu'il comportait: domination sur place des colons, occultation de la législation abolitionniste, maintien formel de la présence coloniale de la France dans l'océan Indien...

2 Autour de Bonaparte, Premier consul, l'opinion était partagée sauf sur la question du maintien du monopole commercial de la colonie avec la métropole. Si une majorité liée au monde des colons penchait en faveur du maintien de l'esclavage là où il n'avait pas été aboli, il y avait aussi des voix discordantes, comme celle du vice-amiral Truguet 
demeuré favorable à l'abolition. En octobre 1800, par exemple, la brève mission à l'île de France de Cossigny Palma s'inscrit dans une perspective abolitionniste, ce qui entraîne l'opposition des colons qui envisagent d'en appeler à l'Angleterre, comme autrefois ceux de la Martinique! Selon Claude Wanquet, telle est la raison principale pour laquelle après bien des oscillations et la recherche de nouveaux compromis, Bonaparte, très hésitant, et les hiérarques du régime consulaire, se rallieront au principe du rétablissement de l'esclavage par la loi du 30 floréal an X (20 mai 1802): date infâme s'il en est de notre histoire nationale mais qui est ici recontextualisée excellemment.

3 Ces brèves indications ne peuvent rendre compte d'un grand livre, nourri d'érudition mais attentif à la synthèse et à la nuance. Ce regard jeté depuis l'océan Indien sur le débat colonial et les résistances opposées aux décisions abolitionnistes, éclaire par ricochet tout ce que l'on sait de la situation aux Antilles et dans la sphère occidentale. L'auteur se montre toujours mesuré dans ses appréciations sur les responsabilités des uns et des autres, de Dufay à Gouly, de Forfait à Truguet, de Boissy d'Anglas à Bonaparte lui-même. Attentif à discuter tous les points de vue, les plus anciens et les récents, le livre de Claude Wanquet nous aide à penser. Mais ce qui demeure, je dirais «en suspens» au terme de la lecture de ce beau travail, c'est la question de l'interaction entre esclavage et domination coloniale d'une part, abolition et intérêt de la métropole d'autre part. C'est le poids respectif de ces facteurs et la représentation qu'on s'en fit qui a sans doute dessiné la dialectique particulière du destin historique des îles, selon qu'elles étaient situées dans l'Atlantique ou dans l'océan Indien. Toute histoire est concrète, même dans le cas de l'esclavage colonial: celle-ci l'est tout particulièrement. 